\title{
Applied Research of Tops is Technology in Contaminated Soil Remediation
}

\author{
Fei $\mathrm{Lu}^{1}$, Jingpo Yang $^{2}$, Jianmei Luo ${ }^{3}$, Jing Chen ${ }^{4}$ \\ ${ }^{1}$ Hebei Provincial Environmental Scientific Research, Shijiazhuang 050000, China \\ ${ }^{2}$ School of Environmental Science \& Engineering, Hebei University of Science and Technology, \\ Shijiazhuang 050018, China \\ ${ }^{3}$ College of Land Resources and Rural-Urban Planning, Shijiazhuang University of Economics, \\ Shijiazhuang 050031, China \\ ${ }^{4}$ Shijiazhuang Qiaodong project preparatory department of sewage treatment, Shijiazhuang 050000, \\ China
}

Keywords: contaminated sites remediation, Multi-Criteria Decision Analysis, Tops is, environmental management.

\begin{abstract}
Multi-objective decision making method can make the evaluation process with intuitive and transparent, easily accepted by the people; rules of its evaluation process and realistic simulation calculation it will help to reduce the decision-making errors; multi-objective decision may also apply to group decision making, integrated consider one or more groups of decision makers multiple views and choose the best balanced solution. Thus managers remediation technology screening methods often used to repair various decision Screening.
\end{abstract}

\section{Introduction}

The current restoration work at contaminated sites of practice and gradually formed a contaminated site remediation management system, but the venue is still in the approval or guide the comment period, the current site remediation management system is not mature, could be improved. ${ }^{[1-3]}$ taking $^{[n}$ into account the outstanding problems of contaminated site remediation technology screening exists, the paper carried out a screening method and its application based Tops is contaminated site remediation technologies.

\section{Contaminated Site Remediation Technology Evaluation Method}

Screening of contaminated sites remediation technology principle is to judge the merits of the standard, that is what kind of repair techniques for the best repair technique. Currently our best remediation technology for contaminated sites not defined, temporary reference to foreign sites using the generally accepted principles of sustainability, and consider the characteristics of immature technology of repair, identified the following technical screening of contaminated site remediation principles: (1) Site the risk is acceptable, repair to an acceptable risk of re-use of the site corresponding to the level of pollutant concentration; (2) repair technology and easy handling, repair controllability strong technical operations, process the unexpected happens less; (3) on the surrounding less affected; (4) size of the project, a reasonable investment; (5) without a significant increase in the cost of repairing the premise to shorten the recovery time.

Screening index evaluation of restoration can refer to varying degrees of detail, too much information would be lost if the indicators are used to score so the way, some have more reference information index evaluation. Advantages Tops is decision method is that it can be evaluated using indicators of objective value, but also to evaluate the numerical score, with good compatibility. In order to better reflect the actual situation of each index in the scoring process used as an objective value score, but there are many indicators are still only a numerical score, specific evaluation methods are as follows. 
Venue Operability: consider the implementation process three categories of natural disturbance conditions: soil physical properties (such as viscosity, permeability, moisture content, particle size, etc.), contaminated media properties (whether in the saturation region, pollution depth, homogeneity etc.), soil chemical properties (egg pH, Eh, CEC, organic matter, etc.). Minus point's method using the index score.

Technology maturity: the number of venues in the United States each repair technology Superfund site remediation implemented as a reference to determine the repair technical maturity.

Total cost: the cost of restoration techniques mainly from information technology screening matrix repair and repair of technical information related summary document.

Repair time, resource requirements, acceptability, secondary pollution / environmental impact of four indicators.

\section{Index weights determined}

Using analytic hierarchy process for the first layer and the second layer relative weights of index weight is calculated, wherein the second layer of technical indicators, economic and environmental indicators corresponding to the judgment matrix are shown in Table 1, Table 2 and Table 3. Consistency index and consistency of judgment matrix ratio CI, CR are 0 , considered judgment matrix basically the same. Right judgment matrix based on the calculated weight of each index are shown in Table 4.

Table 1: The weight of the second layer of technical indicators to determine the corresponding weight matrix

\begin{tabular}{cccc}
\hline & Operability & Applicability of pollutants & Repair time \\
\hline Technical indicators & 1 & 1 & $1 / 3$ \\
Applicability of pollutants & 1 & 1 & $1 / 3$ \\
Repair time & 3 & 3 & 1 \\
\hline
\end{tabular}

Calculated, operability, pollutants applicability, repair time index weights were 0.2, 0.2 and 0.6. Consistency test: $\mathrm{Kmax}=3, \mathrm{CI}=0, \mathrm{RI}=0.58, \mathrm{CR}=0$.

Table 2: right economic indicators to determine the corresponding second layer weight matrix

\begin{tabular}{ccc}
\hline & Total cost & Resource Requirements \\
\hline Total cost & 1 & 7 \\
Resource Requirements & $1 / 7$ & 1 \\
\hline
\end{tabular}

After calculation, the total cost, resource requirements right index weights were $0.875,0.125$. Consistency test: $\mathrm{Kmax}=2, \mathrm{CI}=0, \mathrm{RI}=0, \mathrm{CR}=0$.

Table 3: The right to social environmental indicators corresponding to the second layer of heavy judgment matrix table

\begin{tabular}{ccc}
\hline & Acceptability & Secondary pollution \\
\hline Acceptability & 1 & 1 \\
Secondary pollution & 1 & 1 \\
\hline
\end{tabular}

After calculation, the total cost, resource requirements right index weights were $0.5,0.5$. Consistency test: $\mathrm{Kmax}=2, \mathrm{CI}=0, \mathrm{RI}=0, \mathrm{CR}=0$. 
Table 4: The right of every level indicators corresponding weight coefficient

\begin{tabular}{|c|c|c|c|c|}
\hline \multicolumn{2}{|c|}{ The first layer } & \multicolumn{3}{|c|}{ The second layer } \\
\hline Indicators & Weights & Indicators & $\begin{array}{l}\text { Relative } \\
\text { weights }\end{array}$ & $\begin{array}{l}\text { The total } \\
\text { ordering }\end{array}$ \\
\hline \multirow{3}{*}{ Technical indicators } & \multirow{3}{*}{0.4} & Site operability & 0.2 & 0.08 \\
\hline & & $\begin{array}{l}\text { Applicability of } \\
\text { pollutants }\end{array}$ & 0.2 & 0.08 \\
\hline & & Repair time & 0.6 & 0.24 \\
\hline \multirow{2}{*}{ Economic Indicators } & \multirow{2}{*}{0.4} & The total cost & 0.9 & 0.36 \\
\hline & & Resource burden & 0.1 & 0.04 \\
\hline \multirow{2}{*}{$\begin{array}{l}\text { Environmental } \\
\text { Indicators }\end{array}$} & \multirow{2}{*}{0.2} & Acceptability & 0.5 & 0.1 \\
\hline & & Secondary pollution & 0.5 & 0.1 \\
\hline
\end{tabular}

\section{Evaluation Tops is}

Tops is method first determine a Euclidean space-based evaluation, propose one or more of the ideal candidate repair techniques to repair technique based on the actual situation or venue. Ideal repair technology does not exist in reality, it is only used to describe the best repair technique or worst case when exhibited traits. Then create a function based on the relationship between indicators calculated using various repair techniques to repair the index value and the ideal relative position of technology. Where the best ideals and repair techniques recently, with the worst farthest repair techniques to repair the ideal technology for the best repair technique.

Application and evaluation system of remediation technologies are not mature, the relationship between various indicators is not easy to clear, while establishing a functional relationship requires considerable economic methods, game theory and social psychological knowledge as a basis. Therefore, this article does not establish a functional relationship between indicators, using only vector distance calculation by various repair techniques to repair technique and the ideal length to determine the distance the merits of restoration techniques. Its decision-making method is as follows:

Step One: Build standardized decision matrix:

$$
\begin{aligned}
& A=\left[\begin{array}{ccc}
a_{11} & \cdots & a_{1 j} \\
\vdots & \cdots & \vdots \\
a_{i 1} & \cdots & a_{i j}
\end{array}\right] \\
& r_{i j}=a_{i j} / \sqrt{\sum_{i=1}^{m} a_{i j}{ }^{2}}
\end{aligned}
$$

Step Two: Build the weighted normalized matrix:

$v_{i j}=w_{j} r_{i j}$

The third step: the ideal solution A + to determine the best and worst ideal solution A-:

$$
\begin{aligned}
& A^{+}=\left\{v_{1}^{+}, v_{2}^{+}, \cdots, v_{n}^{+}\right\} \\
& A^{-}=\left\{v_{1}^{-}, v_{2}^{-}, \cdots, v_{n}^{-}\right\} \\
& v_{j}^{+}=\left\{\max \left(v_{i j}\right), j \in C ; \min \left(v_{i j}\right), j \in C^{\prime}\right\} \\
& v_{j}^{-}=\left\{\min \left(v_{i j}\right), j \in C^{\prime} ; \max \left(v_{i j}\right), j \in C\right\}
\end{aligned}
$$

Step Four: Calculate the Euclidean distance to be alternatives Ai and the ideal solution between A + and A-.

$$
\begin{aligned}
& D_{i}^{+}=\sqrt{\left(a_{i j}-v_{i}^{+}\right)^{2}} \\
& D_{i}^{-}=\sqrt{\left(a_{i j}-v_{i}^{-}\right)^{2}}
\end{aligned}
$$


Step Five: relatively close to calculated according to $\mathrm{Di}+$ and $\mathrm{Di}$ - degree $\Delta \mathrm{i}$ :

$\Delta_{i}=D_{i} /\left(D_{i}^{+}+D_{i}^{-}\right)$

Descending treatment alternatives are sorted according to the value $\Delta \mathrm{i}$, ranked first in the program to be selected as the best solution. Features of this evaluation method is this: If a candidate technology has great advantages in certain indicators will significantly increase its technology and distance between the worst repair, whereas if you have a large disadvantage in certain indicators will significantly increase its and the distance between the best repair technique. Election to be repaired by highlighting various technical advantages and disadvantages, so you can choose the repair technique comparative advantages and disadvantages of each potential repair by weighing technology to select the appropriate repair techniques.

\section{Summary}

Contaminated site remediation technology screening is the key to contaminated site remediation, and repair techniques determine the suitability of the site restoration costs and benefits. In this paper, a method Tops is decision chromium slag dumps sites potentially available repair techniques were evaluated. The evaluation found that due to the lack of information of repair techniques, repair techniques using numerical score to determine the extent of the pros and cons are still no substitute for many indicators, and repair techniques on some indicators may have a more detailed and objective reference values. Screening of repair Tops is more appropriate at this stage in a decision-making method.

\section{Acknowledgments}

The authors wish to thank Hebei Provincial department of Science and Technology and Hebei Education Department, Supported by which the present work was possible.

\section{References}

[1] Liqiang Geng, Zhi Chen, Christine W. Chan, et al. An intelligent decision support system for management of petroleum contaminated sites [J]. Expert Systems with Application 20(2001) p. 251-260.

[2] Patrick A. W. van Heesa, Kristin Elgh-Dalgrena, Magnus Enwall. Re-cycling of remediated soil in Sweden: An environmental advantage [J]. Resources, Conservation and Recycling. 2008, 52: p. 1349-1361.

[3] Stephan Volkwein, Hans-Werner Hurtig, Walter Klopffer. Life Cycle Assessment of Contaminated Sites Remediation [J]. The international journal of life cycle assessment. 1999, 4(5): p. 263-274. 